\section{Линецкий Александр Федорович}

доктор экономических наук, доцент, профессор кафедры внешнеэкономической деятельности Уральского государственного

экономического университета, ведущий научный сотрудник Института экономики Уральского отделения Российской академии наук

\section{Оласеинде Олуватосин Давид}

аспирант Уральского государственного

экономического университета

\section{ОСОБЕННОСТИ ВНЕШНЕТОРГОВОЙ ДЕЯТЕЛЬНОСТИ ФЕДЕРАТИВНОЙ РЕСПУБЛИКИ НИГЕРИИ В СОВРЕМЕННЫХ УСЛОВИЯХ}

\section{Аннотация:}

В статье рассмотрены и проанализированы некоторые особенности внешнеторговой деятельно сти Федеративной Республики Нигерии на современном этапе. Установлено, что перед каждым государством в каждый период его развития возникает проблема стратегического выбора - свободная торговля (либерализация) или протекционизм (неопротекционизм). Страны, активно реализующие возможности открытой экономики, способствуют увеличению ее эффективности более высокими темпами, чем страны с протекционистской политикой в сфере внешнеэкономических связей При этом чрезмерная либерализация внешней торговли таит в себе большие риски, связанные, напри мер, с повышением конкуренции отечественных и иностранных предприятий, что может привести к гибели как отдельных производителей, так и иелых отраслей национальной экономики. В Нигерии с начала проведения экономических реформ и принятия соответствующих внешнеторговых стратегий, ориентированных на открытость и развитие внешней торговли, наблюдался достаточно стабильный экономический рост. Авторами сделан вывод о том, что рассмотрение особенностей внешнеторговой деятельности одной из крупных по площади стран в Западной Африке сегодня представляет определенный научный интерес. На ос нове анализа показана важность и необходимость скорейшей корректировки внешнеторговой стратегии Нигерии, направленной на диверсификацию внешней торговли страны и увеличение доли готовой продукции в ее экспорте, что в результате создаст условия для роста нигерийской экономики.

Ключевые слова:

внешнеторговая деятельность, внешнеэкономические связи, Федеративная Республика Нигерия, международная торговля, внешняя торговля, внешнеторговая стратегия, внешнеторговый оборот, экспорт, импорт, товарная структура.

\section{Linetsky Aleksandr Fedorovich}

D.Phil. in Economics, Professor, Foreign Trade Activities Department, Ural State University of Economics, Leading Research Fellow, Institute of Economics, Ural branch of the Russian Academy of Sciences

Olaseinde Oluwatosin David

PhD student, Ural State University of Economics

\section{THE ASPECTS OF FOREIGN TRADE ACTIVITIES IN THE FEDERAL REPUBLIC OF NIGERIA IN THE MODERN CONTEXT}

Summary:

The research considers and analyzes several aspects of present-day foreign trade activities in the Federal Republic of Nigeria. While developing, every state has to make a strategic choice between free trade (liberalization) and protectionism (neo-protectionism). Countries that intensively implement the principles of an open economy rapidly enhance its effectiveness compared to countries following a protectionist policy in the field of foreign economic relations. At the same time, the excessive foreign trade liberalization carries great risks, for example increased competition between domestic and foreign enterprises, which can lead to the loss of both individual producers and entire sectors of the national economy. There has been a stable economic growth in Nigeria since the launch of economic reforms and appropriate foreign trade strategies focusing on foreign trade openness and development. The authors conclude that a study on the aspects of foreign trade activities in one of the largest West African countries is of considerable interest to the scientific community. The research demonstrates the importance and need for an early adjustment of Nigeria's foreign trade strategy aimed at diversifying the country's foreign trade and increasing its export finished products in order to create the conditions for the growth of the Nigerian economy.

Keywords: foreign trade activities, foreign economic relations, Federal Republic of Nigeria, international trade, foreign trade, foreign trade strategy, foreign trade turnover, export, import, commodity structure.

Исследование истории становления и эволюции системы международной торговли показывает наличие тесной взаимозависимости темпов роста внешнеторговой деятельности стран мира и уровня их экономического развития. Чем быстрее развивается внешняя торговля государства, реализующего возможности открытой экономики в качестве альтернативы протекционизму, тем эффрективнее функционирует его национальная экономика. 
Вместе с тем чрезмерная либерализация внешней торговли таит в себе определенные риски, связанные, например, с повышением конкуренции отечественных и иностранных предприятий, что может привести к гибели как отдельных производителей, так и целых отраслей национальной экономики. В связи с этим сегодня каждое государство, в том числе Федеративная Республика Нигерия, на всех этапах своего развития вынуждено делать стратегический выбор: свободная торговля (либерализация) или протекционизм («неопротекционизм», т. е. развитие кроме торгового и промышленного покровительства аграрного, финансового, социального, туристического, культурного протекционизма, что позволяет констатировать формирование нового качества протекционизма - неопротекционизма).

В Нигерии с начала проведения реформ (в 1999 г.) в национальной экономике в целом и во внешнеторговой стратегии в частности, ориентированной на открытость внешней торговли, наблюдался достаточно стабильный рост индикаторов экономического развития. Активизация данным государством внешнеторговой деятельности внесла существенный вклад в повышение эффективности функционирования национальных предприятий и отдельных отраслей, освоение и использование современных технологий. С учетом вышеизложенного тема изучения и анализа особенностей внешнеторговой деятельности одной из крупнейших по площади стран Западной Африки представляется достаточно актуальной и с практической, и с научной точки зрения.

Важным, на наш взгляд, является вопрос об оценке влияния внешней торговли Нигерии на развитие ее экономики. По территориальному устройству государство с развивающейся экономикой на побережье Гвинейского залива, занимающее площадь около 924 тыс. кв. км, представляет собой федеративную республику. По величине территории ей принадлежит 32-е место среди стран мира и 14-е - среди государств Африки. Население Нигерии в 2018 г. составило почти 200 млн человек, по данному показателю страна находится на седьмом месте в мире.

С 18 ноября 1960 г. Нигерия примкнула к Генеральному соглашению по торговле и тарифам, с 1971 г. она - член Организации стран - экспортеров нефти (The Organization of the Petroleum Exporting Countries, ОПЕК), а с начала 1995 г. - член Всемирной торговой организации. Ежесуточная квота рассматриваемого нами государства в ОПЕК составляет ориентировочно 2,2 млн баррелей. В январе 1994 г. Нигерия присоединилась к Конвенции ЭКОВАС об общем внешнем тарифе.

Примерно 40 \% территории этой страны с тропическим климатом используется в сельском хозяйстве, что дает возможность производить и поставлять на экспорт сорго, кешью, какао, арахис, ши, имбирь, бамию, папайю и некоторые другие виды растительной продукции. На нигерийской земле разведаны значительные запасы полезных ископаемых и минеральных ресурсов (нефти, природного газа, олова, железной руды, ниобия, свинца, угля, известняка, цинка и др.), большая часть которых экспортируется.

Активная фаза роста добычи и поставок на внешний рынок углеводородов приходится на 70-е гг. XX в. До этого периода в экспорте Нигерии преобладали сельскохозяйственные товары. Сельскохозяйственная отрасль обеспечивала занятость около трех четвертей трудоспособного населения государства. Во время активизации процесса извлечения углеводородных ресурсов значительно уменьшилась площадь пахотных земель и сократилось производство сельскохозяйственной продукции. Федеративная Республика Нигерия стала чувствительной к колебаниям мировых цен на нефть. При этом на фоне значительных темпов роста населения для удовлетворения потребностей в стране, и без того многонаселенной, появилась необходимость импортировать товары, в том числе продукты питания, табачные изделия и др. Кроме того, вследствие низкого уровня научно-технического и технологического развития в Нигерии всегда существовала потребность в импортных высокотехнологичных товарах (оборудовании, транспортных средствах, химических веществах, иных) с высокой степенью переработки и готовности, что обусловило ее товарную структуру импорта.

В колониальный период самым крупным государством - внешнеторговым партнером Нигерии была Англия. В 1960 г. после провозглашения суверенитета Федеративная Республика Нигерия реализовала ряд мер по диверсификации своей внешнеторговой стратегии, в том числе несколько изменился перечень государств - внешнеторговых партнеров. В настоящее время список государств, с которыми торгует Нигерия, насчитывает ежегодно около 100 стран мира. Основной ее внешнеторговый партнер - Китайская Народная Республика, торговля с нею составляет приблизительно четверть всей внешней торговли государства на побережье Гвинейского залива. Крупными внешнеторговыми партнерами также выступают Германия, Франция, Нидерланды, Канада, Япония, Италия и Испания. С учетом незначительных объемов экспорта и импорта Нигерии ее доля в общем объеме международной торговли является довольно низкой, что наглядно демонстрирует в таблице 1 динамика изменения показателей внешней торговли данной страны и ее доли в мировом экспорте и импорте в 2014-2017 гг. 
Таблица 1 - Динамика внешней торговли Нигерии и ее удельный вес в общем объеме мирового экспорта и импорта в 2014-2017 гг., млрд долл. США [1]

\begin{tabular}{|l|c|c|c|c|}
\hline \multicolumn{1}{|c|}{ Показатели Нигерии } & $\mathbf{2 0 1 4}$ & $\mathbf{2 0 1 5}$ & $\mathbf{2 0 1 6}$ & $\mathbf{2 0 1 7}$ \\
\hline Экспорт & 97 & 81,9 & 46,9 & 49,2 \\
\hline Импорт & 54,9 & 61 & 53,4 & 50,6 \\
\hline Внешнеторговый оборот & 151,9 & 142,9 & 100,3 & 112,4 \\
\hline Объем мирового экспорта & 18301 & 17779 & 18494 & 18561 \\
\hline Объем мирового импорта & 18409 & 18641 & 18641 & 18494 \\
\hline Доля экспорта страны в мировом экспорте, \% & 0,53 & 0,46 & 0,25 & 0,27 \\
\hline Доля импорта страны в мировом импорте, \% & 0,30 & 0,32 & 0,29 & 0,25 \\
\hline
\end{tabular}

Таким образом, Нигерия в 2014-2017 гг. не только имела незначительную долю в мировом объеме экспорта и импорта, но и сократила ее в указанный период с 0,53 до 0,27 \% и с 0,3 до 0,25 \% соответственно. По объему валового внутреннего продукта (ВВП), который в 2016 г. исчислялся в размере 485 млрд долл. США, она занимает достаточно престижное 24-е место среди всех стран мира. Но в расчете на душу населения ВВП составляет лишь 2,64 тыс. долл. США, что соответствует в мировом рейтинге 177-му месту. В 2016 г. удельный вес внешнеторгового оборота Нигерии (100,3 млрд долл. США) в объеме ВВП (485 млрд долл. США) равен 20,7 \%. Считается, что данный показатель определяет, насколько внешнеторговая деятельность страны стимулирует ее экономический рост. При этом внешняя торговля оказывает ощутимое позитивное воздействие на темпы экономического развития государства только в том случае, если достигнута и превышена доля объема внешнеторгового оборота к ВВП в размере примерно $25 \%$ [2].

На основании приведенных сведений можно сделать вывод о том, что внешняя торговля Нигерии в современных условиях пока не является эффективным инструментом влияния на рост национальной экономики. Ввиду этого существует острая необходимость в реализации в перспективе комплекса оперативных мер по диверсификации и стимулированию внешнеторговой, прежде всего экспортной, деятельности страны. Характеризуя проблему экспорта из Федеративной Республики Нигерии, следует отметить, что нефть и нефтепродукты в ее экономике - ценные природные ресурсы, занимающие лидирующие позиции в экспорте страны, обеспечивая свыше $90 \%$ от его общего объема. Среди стран - экспортеров углеводородного сырья рассматриваемое нами государство занимает восьмое место в мире. Несмотря на широкомасштабные усилия по либерализации внешней торговли, соответствующая статья экспорта находится под жестким государственным контролем. Главным регулирующим и контролирующим органом в этой сфрере деятельности является Национальная нефтяная корпорация Нигерии (NNOC).

Итак, до 70-х гг. прошлого столетия сельхозпродукция в Нигерии была главной экспортной позицией. После того, как в экономике этой страны лидирующее положение заняла нефтяная отрасль, сельское хозяйство стало иметь второстепенное значение. Однако сельскохозяйственный сектор по-прежнему обеспечивает занятость около 70 \% всего работающего населения Федеративной Республики Нигерии. Основными статьями экспорта Нигерии в наши дни остаются нефртепродукты, какао и древесина, что отражено в таблице 2. Самыми крупными странами внешнеторговыми партнерами Нигерии в ее экспорте, как показано на рисунке 1, считаются Индия $(21 \%)$, Нидерланды (14\%) и Испания (11\%).

Таблица 2 - Товарная структура экспорта Нигерии в 2017 г. [3]

\begin{tabular}{|c|c|c|}
\hline Товар & Объем, долл. США & $\begin{array}{c}\text { Доля в общем } \\
\text { объеме экспорта, \% }\end{array}$ \\
\hline Oil \& Mineral Fuels (нефть и минеральное топливо) & 93,0 млрд & 53 \\
\hline Ships \& Boats (корабли и лодки) & 2,0 млрд & 12 \\
\hline Explosives (взрывчатые вещества) & 2,0 млрд & 12 \\
\hline Сосоа (какао) & 1,0 млрд & 6 \\
\hline Textile Articles (текстильные изделия) & $712 \mathrm{млн}$ & 4 \\
\hline Industrial Machinery (промышленное оборудование) & $631 \mathrm{млн}$ & 4 \\
\hline Hides \& Leather (шкуры и кожа) & $591 \mathrm{млн}$ & 4 \\
\hline Oil Seeds (масляные семена) & 558 млн & 3 \\
\hline Cotton (хлопок) & 197 млн & 1 \\
\hline Aluminum (алюминий) & $149 \mathrm{млн}$ & 1 \\
\hline
\end{tabular}




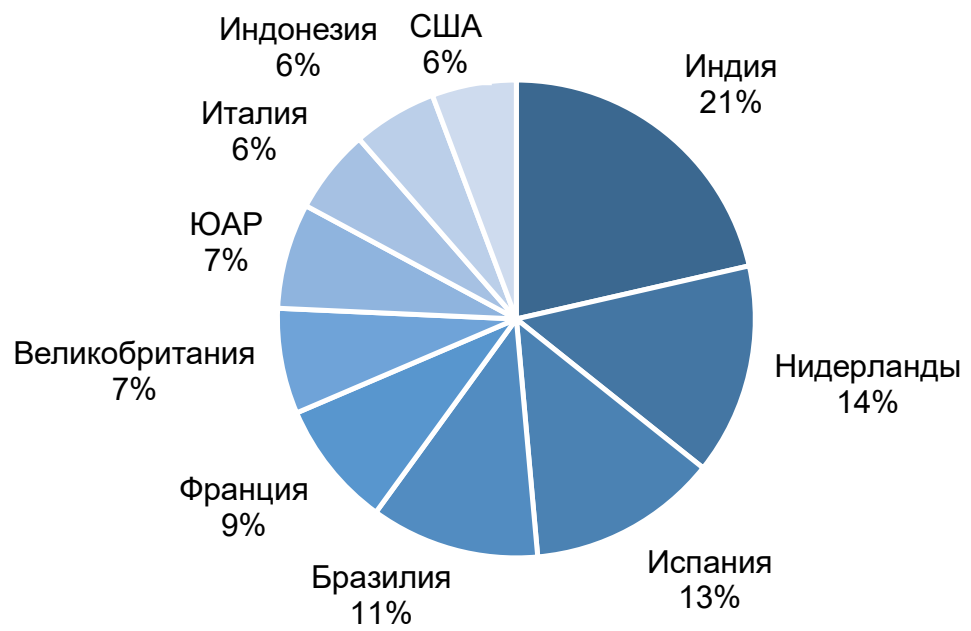

\section{Рисунок 1 - Основные страны, являющиеся внешнеторговыми партнерами} в экспорте Нигерии в 2017 г. [5]

Основные товары в импорте Федеративной Республики Нигерии - машины, тяжелое оборудование, товары народного потребления и продукты питания. Об этом можно сделать вывод, учитывая показатели, представленные в таблице 3.

Таблица 3 - Товарная структура импорта Нигерии в 2017 г. [5]

\begin{tabular}{|l|c|c|}
\hline \multicolumn{1}{|c|}{ Товар } & $\begin{array}{c}\text { Объем, млрд долл. } \\
\text { СшА }\end{array}$ & $\begin{array}{c}\text { Доля в общем } \\
\text { объеме импорта, \% }\end{array}$ \\
\hline Oil \& Mineral Fuels (нефть и минеральное топливо) & 7,6 & 24 \\
\hline Industrial Machinery (промышленное оборудование) & 7,0 & 22 \\
\hline Motor Vehicles \& Parts (автомобили и запчасти) & 4,0 & 13 \\
\hline Electrical Machinery (электрические машины) & 3,5 & 8 \\
\hline Cereals (хлопья) & 2,4 & 6 \\
\hline Plastics (пластмассы) & 2,0 & 6 \\
\hline Iron \& Steel Articles (изделия из железа и стали) & 1,8 & 4 \\
\hline Iron \& Steel (железная сталь) & 1,3 & 3 \\
\hline Seafood (морепродукты) & 1,0 & 3 \\
\hline Sugar \& Confectionerу (сахар и кондитерские изделия) & 1,0 & \\
\hline
\end{tabular}

Значительная часть импорта поступает из Евросоюза, в частности из Нидерландов, Великобритании, Франции и Германии, о чем свидетельствует рисунок 2.

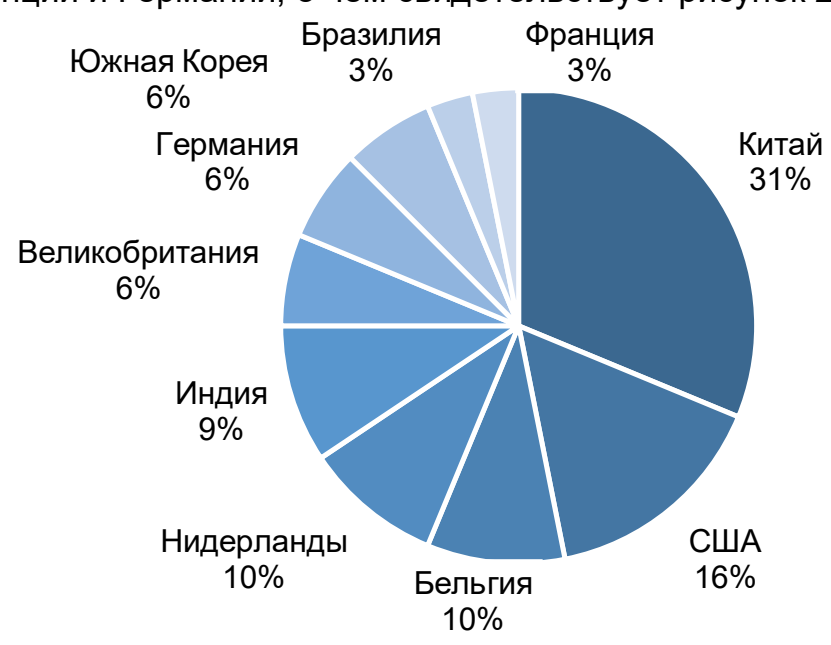

Рисунок 2 - Основные страны, являющиеся внешнеторговыми партнерами в импорте Нигерии в 2017 г. [6]

В импорте Нигерия интенсивно развивает торговые отношения с такими государствами, как Китай, Индия и Южная Корея. После США Индия является вторым по величине импортером 
нигерийской нефти. Внешняя торговля в глобальной экономике стала важнейшим фрактором социально-экономического развития стран мира. Участие Нигерии в международном обмене товарами и услугами играет все более ощутимую роль в развитии экономики страны. Внешняя торговля - источник валютных поступлений и ее дополнительных доходов. Влияние внешней торговли на социально-экономическое положение анализируемого государства в Западной Африке заключается в том, что:

1) активизация экспортной деятельности логично влечет за собой потребность в повышении объема производства экспортного продукта, в организации сопутствующих производств и, следовательно, в увеличении привлекаемой для этих целей рабочей силы, что приведет к росту процента занятости трудоспособного населения;

2) импортная деятельность по поставкам в страну высокотехнологичной продукции создает предпосылки для национальных предприятий в повышении качества аналогичных производимых отечественных товаров либо в организации их производства с целью импортозамещения;

3) экспортная деятельность обеспечивает поступление иностранной валюты, которая используется для осуществления импортных закупок и решения многочисленных социальных проблем в здравоохранении, образовании и инфраструктуре страны;

4) импортные поставки в страну высокотехнологичных товаров позволяют повысить технологический уровень национального производства, а также грамотность и профессионализм работающих;

5) внешняя торговля создает условия и активизирует развитие малого и среднего бизнеса, который, наращивая участие во внешней торговле, повышает объемы и эффективность своей деятельности;

6) активизация участия в международной торговле позволяет государству иметь положительный платежный баланс, устранять многие экономические и социальные проблемы.

Таким образом, Федеративная Республика Нигерия заинтересована в активизации своего участия в международном разделении труда и обладает для реализации этой цели широкими возможностями. В стране огромные природные ресурсы, обеспечивающие сравнительно низкие издержки при их добыче; значительные трудовые ресурсы и относительно низкая стоимость рабочей силы на всех уровнях.

Однако существуют трудности и национальные проблемы, негативно влияющие на развитие внешней торговли в данном государстве. Во-первых, после активизации нефтедобычи и ее экспорта возникла сильная зависимость страны от поставок углеводородов за рубеж и мировых цен на него. При этом в экспортной структуре страны нефтепродукты имеют долю свыше $90 \%$. Во-вторых, на нигерийской земле не создана либо не развита финансовая, транспортная, логистическая и коммуникационная инфраструктура в сфере внешнеторговой деятельности. Данное обстоятельство не позволяет экспортно ориентированным предприятиям активно осуществлять поставки ряда конкурентоспособных высококачественных товаров на зарубежный рынок. В-третьих, в стране практически отсутствует система государственной поддержки экспорта готовой и высокотехнологичной продукции. В этой сфере не разработаны и не приняты какие-либо государственные программы по финансированию, кредитованию и субсидированию экспортеров.

С целью увеличения объемов и повышения эффективности внешней торговли Нигерии, по мнению авторов, необходимо организовать ряд мероприятий. В частности, Федеративная Республика Нигерия должна определить и реализовать комплекс мер по диверсификации своего экспорта. Сельское хозяйство, развивающееся у нигерийцев, по-прежнему признается перспективным потенциальным источником для увеличения экспорта. На уровне государства целесообразно использовать весь арсенал инструментов для развития сельского хозяйства и обрабатывающей промышленности в дальнейшем, что повысит устойчивость национальной экономики и снизит зависимость страны от колебания мировых цен на углеводороды. Следует разработать государственные программы по поддержке и содействию развития малого и среднего бизнеса; по финансированию, субсидированию и кредитованию компаний, осуществляющих экспортную деятельность либо имеющих потенциал для ее осуществления, что будет стимулировать рост объема экспорта страны. Требуются масштабные меры государственной поддержки по созданию и развитию финансовой, транспортной, производственной инфраструктуры, направленной на развитие экспорта готовой качественной продукции с высокой степенью переработки. Для обеспечения государства высококвалифицированной рабочей силой крайне важно изыскать и привлечь дополнительные источники финансирования образовательных программ, что в будущем создаст возможность производства и развития экспорта конкурентоспособных готовых изделий.

В настоящее время Нигерия обладает значительным потенциалом и огромными возможностями для стимулирования внешнеторговой деятельности в перспективе. Однако для их эффективного использования необходимы качественный и количественный рывок в экономическом 
развитии, существенная корректировка стратегии развития внешней торговли государства, направленной прежде всего на наращивание экспорта переработанной и готовой продукции.

С точки зрения авторов, важным направлением расширения и развития внешней торговли анализируемого государства, способствующим реализации имеющегося внешнеэкономического потенциала, станет активизация участия страны в международной экономической интеграции и вхождение в состав различных интеграционных группировок, например в Андское сообщество, Экономическое сообщество государств Западной Африки (ЭКОВАС) и др. Увеличение доли внешнеторгового оборота в ВВП Нигерии придаст импульс и создаст дополнительные условия для роста национальной экономики. Несмотря на преодолеваемые сегодня национальные проблемы в социально-экономической сфере, данная страна должна продолжать активно позиционировать себя на мировой арене как государство, проявляющее готовность участвовать и содействовать усилиям стран мира в решении глобальных социально-экономических проблем. Это обстоятельство позволит улучшить имидж государства и нарастить образовательный, профессиональный уровень работающего населения.

\section{Ссылки:}

1. Nigeria [Электронный ресурc]. URL: http://atlas.media.mit.edu/en/profile/country/nga (дата обращения: 20.02.2019).

2. Казанцев С.К., Стровский Л.Е., Шаблова Е.Г. Внешнеэкономическая деятельность предприятия : учебник / под ред. Л.Е. Стровского. М., 2012. 503 с.

3. Asiodu P.C. Industrial Policy and Incentives in Nigeria // Nigerian Journal of Economics and Social Studies. 1967. Vol. 9, iss. 2. P. 161-174 ; Nigeria: Trade Statistics [Электронный ресурc]. URL: https://globaledge.msu.edu/countries/nigeria/tradestats (дата обращения: 20.02.2019).

4. The World Integrated Trade Solution [Электронный ресурc]. URL: https://wits.worldbank.org/CountryProfile/en/Country/NGA (дата обращения: 20.02.2019).

5. Killick T. The Role of the Public Sector in the Industrialization of the African Developing Countries / UNIDO. Vienna, 1981.

6. The World Integrated Trade Solution.

\section{References:}

Asiodu, PC 1967, 'Industrial Policy and Incentives in Nigeria', Nigerian Journal of Economics and Social Studies, vol. 9, iss. 2, pp. 161-174.

Kazantsev, SK, Strovsky, LE \& Shablova, EG 2012, Foreign Economic Activity of the Enterprise: a textbook, Moscow, 503 p., (in Russian).

Killick, T 1981, The Role of the Public Sector in the Industrialization of the African Developing Countries, UNIDO, Vienna.

Nigeria 2019, viewed 20 February 2019, <http://atlas.media.mit.edu/en/profile/country/nga>

Nigeria: Trade Statistics 2019, viewed 20 February 2019, <https://globaledge.msu.edu/countries/nigeria/tradestats >. try/NGA>.

The World Integrated Trade Solution 2019, viewed 20 February 2019, <https://wits.worldbank.org/CountryProfile/en/Coun- 